Braz J Med Biol Res, October 2012, Volume 45(10) 948-954

doi: $10.1590 / \mathrm{S} 0100-879 X 2012007500122$

Effect of the 5- $\mathrm{HT}_{4}$ receptor and serotonin transporter on visceral hypersensitivity in rats

Chi Yan, Liu Xin-Guang, Wang Hua-Hong, Li Jun-Xia and Li Yi-Xuan

The Brazilian Journal of Medical and Biological Research is partially financed by

\section{贵CNPq}

da Ciência e Tecnologia

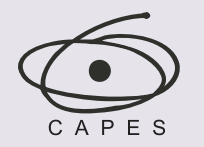

Ministério da Educação
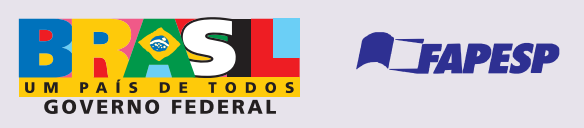

Institutional Sponsors

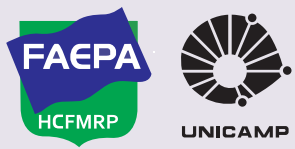

$\oplus$ SHIMADZU
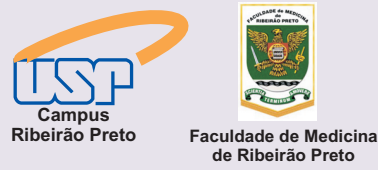

UNICAMP
Volume 45 (10) 875-994 October 2012

BIOMEDICAL SCIENCES 


\title{
Effect of the $5-\mathrm{HT}_{4}$ receptor and serotonin transporter on visceral hypersensitivity in rats
}

\author{
Chi Yan, Liu Xin-Guang, Wang Hua-Hong, Li Jun-Xia and Li Yi-Xuan \\ Department of Gastroenterology, Peking University First Hospital, Beijing, China
}

\begin{abstract}
Visceral hypersensitivity plays an important role in motor and sensory abnormalities associated with irritable bowel syndrome, but the underlying mechanisms are not fully understood. The present study was designed to evaluate the expression of the $5-\mathrm{HT}_{4}$ receptor and the serotonin transporter (SERT) as well as their roles in chronic visceral hypersensitivity using a rat model. Neonatal male Sprague-Dawley rats received intracolonic injections of $0.5 \%$ acetic acid $(0.3-0.5 \mathrm{~mL}$ at different times) between postnatal days 8 and 21 to establish an animal model of visceral hypersensitivity. On day 43, the threshold intensity for a visually identifiable contraction of the abdominal wall and body arching were recorded during rectal distention. Histological evaluation and the myeloperoxidase activity assay were performed to determine the severity of inflammation. The $5-\mathrm{HT}_{4}$ receptor and SERT expression of the ascending colon were monitored using immunohistochemistry and Western blot analyses; the plasma 5-HT levels were measured using an ELISA method. As expected, transient colonic irritation at the neonatal stage led to visceral hypersensitivity, but no mucosal inflammation was later detected during adulthood. Using this model, we found reduced SERT expression $(0.298 \pm 0.038$ vs $0.634 \pm 0.200, \mathrm{P}<0.05)$ and increased $5-\mathrm{HT}_{4}$ receptor expression $(0.308 \pm 0.017$ vs $0.298 \pm 0.021$, $\mathrm{P}<0.05)$. Treatment with fluoxetine $\left(10 \mathrm{mg} \cdot \mathrm{kg}^{-1} \cdot \mathrm{day}^{-1}\right.$, days $\left.36-42\right)$, tegaserod $\left(1 \mathrm{mg} \cdot \mathrm{kg}^{-1} \cdot \mathrm{day}^{-1}\right.$, day 43$)$, or the combination of both, reduced visceral hypersensitivity and plasma 5-HT levels. Fluoxetine treatment increased 5- $\mathrm{HT}_{4}$ receptor expression $(0.322 \pm 0.020$ vs $0.308 \pm 0.017, \mathrm{P}<0.01)$ but not SERT expression $(0.219 \pm 0.039$ vs $0.298 \pm 0.038, P=0.654)$. These results indicate that both the $5-\mathrm{HT}_{4}$ receptor and SERT play a role in the pathogenesis of visceral hypersensitivity, and its mechanism may be involved in the local 5-HT level.
\end{abstract}

Key words: 5-Hydroxytryptamine receptor 4; Serotonin; Serotonin transport protein; Visceral hypersensitivity

\section{Introduction}

Irritable bowel syndrome (IBS) is a common gastrointestinal $(\mathrm{Gl})$ disorder associated with alterations in motility, secretion, and visceral sensation (1). Although the pathophysiology of IBS is not fully understood, it is believed that visceral hypersensitivity is responsible for the motor and sensory abnormalities in patients with this condition (2). Since the serotonin (5-HT) signaling pathway plays a significant role in visceral hypersensitivity (3), it is of interest to determine the role of this pathway in the pathogenesis of IBS.

As an important neurotransmitter and neuromodulator, serotonin released by enterochromaffin cells (EC) promotes peristalsis, secretion, vasodilation, and sensory signaling in the gut via different subtypes of serotonergic receptors $(1,4)$. Serotonin is involved in the regulation of both motor and sensory functions of the $\mathrm{Gl}$ tract (5). Accumulating evidence suggests that serotonergic signaling is altered in the gut of IBS patients, including alterations in 5-HT biosynthesis, content, release, and/or reuptake $(6,7)$. However, the status of serotonergic receptors and their role in the pathogenesis of IBS are not clear.

As a membrane protein that mediates the inactivation of serotonin, the serotonin transport protein (SERT) plays a significant role in terminating transmitter action and maintaining transmitter homeostasis (8). Its role in the onset and development of IBS has been suggested $(6,9)$, although the exact mechanisms of action remain unknown.

Colon irritation in neonatal rats has been widely used as an animal model of IBS to study chronic visceral hypersensitivity. In this model, abnormal stimulation of the GI

Correspondence: Chi Yan, Department of Gastroenterology, Peking University First Hospital, Beijing, 100034, China.

Fax: +86-10-6655-1580. E-mail: chiyan@263.net

Received September 14, 2011. Accepted July 11, 2012. Available online July 27, 2012. Published September 3, 2012. 
tract during postnatal development can have a long-lasting impact on the neural processing of sensory information in adulthood $(10,11)$, which does not result in any pathological changes in colon mucosa. In this study, we used acetic acid to induce colon irritation in order to develop an animal model of IBS, which has proven to be a validated model for persistent visceral hypersensitivity (12), and then evaluated the changes in the $5-\mathrm{HT}_{4}$ receptor and SERT expression. Additionally, we investigated whether SERT and 5- $\mathrm{HT}_{4}$ receptor can influence visceral hypersensitivity through their impact on 5-HT signaling by using pharmacological modulators, including fluoxetine, a selective serotonin reuptake inhibitor (SSRI) (13), and tegaserod, a partial agonist of the $5-\mathrm{HT}_{4}$ receptor (14).

\section{Material and Methods}

\section{Animals}

In order to avoid the influence of estrogens on visceral sensitivity, we used male rats to develop the animal models. Male neonate Sprague-Dawley rats were provided by the Peking University Laboratory Animal Center. Rats were housed in plastic cages containing soft bedding and maintained at $23-24^{\circ} \mathrm{C}$ on a $12 / 12-\mathrm{h}$ light/dark cycle. Ten neonates were housed per cage with 1 adult female rat until they were 25 days old. The adult female had access to food and water ad libitum. After separation, 4 male rats were housed per cage with free access to food and water. The study protocol was reviewed and approved by the Animal Ethics Committee of the First Hospital, Peking University.

\section{Protocol}

Neonatal male Sprague-Dawley rats were randomly divided into 5 groups for different treatments. Group 1 received colonic infusion of $0.9 \%$ saline as the control group. Groups 2 to 5 received $0.5 \%$ acetic acid between postnatal days 8 and 21 ( $0.3 \mathrm{~mL}$ daily for days $8-14$ and $0.5 \mathrm{~mL}$ daily for days 15-21). The infusion was performed through a coronary arteriography catheter inserted $2 \mathrm{~cm}$ from the anus. After
2 weeks of treatment with acetic acid, the animals were maintained for 2 weeks without any additional treatment. At 5 weeks of age, groups 3 and 5 received fluoxetine (a generous gift from Shanghai Zhongxi Pharmaceutical Group Co., Ltd., China) at an ip dose of $10 \mathrm{mg} \cdot \mathrm{kg}^{-1} \cdot \mathrm{day}^{-1}$ for one week. Groups 1, 2, and 4 received $0.9 \%$ saline as control. At day 43, groups 4 and 5 received tegaserod (a generous gift from Novartis, Switzerland) at a dose of $1 \mathrm{mg} / \mathrm{kg}$, ip, and the other groups received $0.9 \%$ saline as control. Thirty minutes after administering tegaserod or saline, we evaluated the visceral sensitivity of all groups. At the end of the experiments, all rats (8 per group) were euthanized, samples were taken, and the inflammation status of the colon was evaluated. The doses of drugs used in the study were based on effective doses previously described in the literature $(15,16)$. Table 1 depicts the experimental schedule for each group.

\section{Evaluation of visceral sensitivity}

At day 43, the threshold intensity, which induces a visually identifiable contraction of the abdominal wall and body arching, was recorded during rectal distention to evaluate visceral hypersensitivity. After 30 min of adaptation in small Lucite cubicles $(20 \times 8 \times 8 \mathrm{~cm})$, rectal distention was performed using the 6F Fogarty arterial embolectomy catheter (Edwards Lifesciences LLC, USA) in the descending colon ( $1 \mathrm{~cm}$ from the anal verge) with increasing volumes of saline in increments of $20 \mu \mathrm{L}$, starting at $100 \mu \mathrm{L}$. For each measurement, the rats were given rectal distention for 20 $\mathrm{s}$ every $2 \mathrm{~min}$. The measurements were repeated three times for accuracy, and the difference between replicate measurements was $<20 \%$.

\section{Assessment of colonic inflammation}

Segments from the proximal colons of rats of groups 1 and 2 were collected and embedded in $10 \%$ paraffin for histological examination. Sections of $4 \mu \mathrm{m}$ were cut and processed for hematoxylin-eosin staining. A pathologist blind to the group assignment reviewed the slides.

Table 1. Protocol for the induction of visceral hypersensitivity in neonatal Sprague-Dawley rats ( $N=8$ per group) and treatment with fluoxetine and tegaserod.

\begin{tabular}{|c|c|c|c|c|}
\hline \multirow[t]{2}{*}{ Group } & \multicolumn{2}{|c|}{$\begin{array}{c}\text { Daily colonic irritation with } \\
0.5 \% \text { acetic acid }\end{array}$} & \multicolumn{2}{|l|}{ Treatment } \\
\hline & $\begin{array}{l}\text { Days } 8-14 \\
\text { (dose } 0.3 \mathrm{~mL} \text { ) }\end{array}$ & $\begin{array}{l}\text { Days } 15-21 \\
\text { (dose } 0.5 \mathrm{~mL} \text { ) }\end{array}$ & $\begin{array}{l}\text { Daily fluoxetine days } 36-42 \\
\quad\left(10 \mathrm{mg} \cdot \mathrm{kg}^{-1} \cdot \text { day }^{-1}, \mathrm{ip}\right)\end{array}$ & $\begin{array}{l}\text { Tegaserod day } 43 \\
(1 \mathrm{mg} / \mathrm{kg}, i p)\end{array}$ \\
\hline Control group & - & - & - & - \\
\hline Hypersensitive group & + & + & - & - \\
\hline Fluoxetine group & + & + & + & - \\
\hline Tegaserod group & + & + & - & + \\
\hline Fluoxetine and tegaserod group & + & + & + & + \\
\hline
\end{tabular}


The myeloperoxidase (MPO) activity assay was performed to quantify the severity of inflammation. MPO content was measured by the method described by Krawisz et al. (17). Briefly, a 1-cm segment of the proximal colon was collected by laparotomy, minced in $1 \mathrm{~mL}$ ice-cold $0.9 \%$ saline, homogenized, diluted to a concentration of $5 \%$ homogenate, and then analyzed colorimetrically according to manufacturer instructions (A044, Nanjing Jiancheng Bioengineering Institute, China); the change in absorbance at $460 \mathrm{~nm}$ was measured.

\section{Measurement of 5-HT in plasma}

Measurement of 5-HT was performed according to the method described by Linden et al. (18). Blood samples from the vein of the inner canthus were collected into a heparinized tube and centrifuged at $1000 \mathrm{~g}$ for $5 \mathrm{~min}$ at room temperature; plasma samples were then collected and stored in $-70^{\circ} \mathrm{C}$ until analysis. Aliquots of each sample were taken and 5-HT levels were determined using an enzyme immunoassay kit (3B081, RapidBio, USA) according to manufacturer instructions. The absorbance was read at 450 $\mathrm{nm}$ and the corresponding concentration was determined from the standard curve.

\section{Immunohistochemistry}

Segments of the proximal colon were embedded in $10 \%$ paraffin and $5-\mu \mathrm{m}$ thick sections were prepared for immunohistochemistry. The standard protocol for the immunostaining of the 5- $\mathrm{HT}_{4}$ receptor was followed as Ref. 19. The primary antiserum used was rabbit antibody to $5-\mathrm{HT}_{4}$ receptor at 1:600 dilution (S1001-20, UsBio Company, USA) and the detection was performed using the Two-Step IHC Detection Reagent (GBI, USA). Positive development of $5-\mathrm{HT}_{4}$ receptor was visualized by DAB staining. To quantify the $5-\mathrm{HT}_{4}$ receptor signal intensities, the tissue sections were digitized at a single exposure with a 20X objective. Each sample was evaluated in 3 continuous sections and 3 random fields in each section. The mean gray values of immunoreactivity in the mucosal layer of these images were determined using the Leica Qwin image processing and analysis software (Germany).

\section{Western blot analysis}

After removal, the segments of the proximal colon were immediately frozen in liquid nitrogen and stored at $-70^{\circ} \mathrm{C}$ until analysis by Western blotting. The tissue samples were homogenized in $0.5 \mathrm{~mL}$ ice-cold RIPA Lysis Buffer $(50 \mathrm{mM}$ Tris- $\mathrm{HCl}, \mathrm{pH} 7.4,150 \mathrm{mM} \mathrm{NaCl}, 1 \% \mathrm{NP}-40,0.1 \%$ SDS) and the homogenates were centrifuged at $15,000 \mathrm{~g}$ for $10 \mathrm{~min}$ at $4{ }^{\circ} \mathrm{C}$. The supernatant was collected and its protein concentration was determined using Coomassie brilliant blue. Western blotting was performed by the method of Bian et al. (20), but with slight modifications. Samples with $100 \mu \mathrm{g}$ total proteins were loaded onto a $10 \%$ SDS-PAGE for separation and then transferred to a nitrocellulose membrane. Mem- branes were then blocked with 5\% milk in TBS-Tween 20 buffer for $1 \mathrm{~h}$, incubated at $4^{\circ} \mathrm{C}$ overnight with a 1:300 diluted rabbit polyclonal anti-rat SERT (AB1594P, Chemicon, USA), washed 3 times with Tris-buffered saline Tween, and then incubated for $1 \mathrm{~h}$ with $\mathrm{HRP}$-conjugated goat anti-rabbit IgG antibody (1:8000 diluted, Santa Cruz Biotechnology, USA). Enhanced chemiluminescence (Millipore, USA) was used to visualize the immunoreactive proteins. The absorbance of the protein bands was measured with the AlphaEaseFC Imaging software (Alpha Innotech Corporation, USA) and normalized to the intensity of $\beta$-actin.

\section{Statistical analysis}

Data are reported as means \pm SEM. Statistical analyses were performed using SPSS11.0. Comparisons between 2 groups were performed using the Student $t$-test. Comparisons between multiple groups were performed using ANOVA. Differences with a $P$ value $<0.05$ were considered to be statistically significant.

\section{Results}

\section{Visceral hypersensitivity}

In this animal model, we observed visceral hypersensitivity in adult rats when they were subjected to transient colonic irritation with $0.5 \%$ acetic acid during the neonatal age. Rats were tested for sensitivity to colorectal distention on day 43. A significantly lower threshold of abdominal wall contraction and body arching in response to increasing colorectal distension was observed in neonatal rats treated with acetic acid than in the controls $(0.19 \pm 0.06$ vs $0.40 \pm$ $0.14 \mathrm{~mL}$ for abdominal muscle contraction and $0.47 \pm 0.13$ vs $0.91 \pm 0.26 \mathrm{~mL}$ for body arching, $\mathrm{P}<0.01$, $t$-test, $\mathrm{N}=8$ ). There was no difference in body weight between Group 1 and Group 2 at any time. Histological examination showed no significant structural damage to colonic tissues. MPO level, an index of inflammation and neutrophil infiltration of tissue (21), was similar for the two groups $(0.623 \pm 0.739$ vs $0.497 \pm 0.570, \mathrm{P}=0.724 ; \mathrm{N}=8$ ).

These results indicate that transient colonic irritation due to $0.5 \%$ acetic acid in neonatal rats has no significant effects on the growth and development or on the tissue histology of the colon mucosa of adults, but can lead to visceral hypersensitivity. This is thus a suitable model for mechanistic studies of chronic visceral hypersensitivity and IBS.

\section{Effects of tegaserod and fluoxetine on visceral sensitivity}

In order to understand the possible role of $5-\mathrm{HT}_{4}$ receptor and SERT in visceral hypersensitivity, we used two related drugs. As illustrated in Figure 1, both tegaserod, a partial $5-\mathrm{HT}_{4}$ receptor agonist, and fluoxetine, a selective serotonin reuptake inhibitor, reduced visceral hypersensitivity. The effect of fluoxetine seemed to be more evident on low volume distention (Figure 1), indicating that this drug interferes with 
hyperreflexia due to enhanced nociception. The doses of the drugs used in the study were based on effective doses previously described in the literature $(15,16)$.

\section{Plasma 5-HT}

Peripheral 5-HT can cause hyperalgesia. SERT can influence the local 5-HT level by uptake into neuronal cells. Tegaserod can also lead to changes in the local 5-HT level since the $5-\mathrm{HT}_{4}$ receptor can regulate $5-\mathrm{HT}$ release from EC cells. In order to understand the relationship between 5-HT level, visceral hypersensitivity and these 2 drugs, we measured the peripheral 5-HT level. A previous study showed that $5-\mathrm{HT}$ in platelet-depleted plasma can be used as an estimate for serotonin release from the intestinal mucosa (22). In the present study, we found that, compared with the hypersensitivity group, treatment with fluoxetine, tegaserod, or their combination reduced 5-HT levels (Figure 2). These results indicate that SERT and the $5-\mathrm{HT}_{4}$ receptor influence visceral hypersensitivity partly by modulating peripheral 5-HT levels.

\section{SERT expression}

To determine whether SERT expression was altered in adult rats that were sensitized with acetic acid as neonates, we measured SERT expression in colonic tissues. Figure 3 shows that neonatal colonic irritation can cause a reduction of SERT expression in adults. Fluoxetine treatment had no effect on SERT expression. Since protein expression is a long-term process, we did not measure SERT expression in the tegaserod-treated group.

\section{5- $\mathrm{HT}_{4}$ receptor expression}

We next examined whether $5-\mathrm{HT}_{4}$ receptor expression was changed in adult rats that were sensitized with acetic acid as neonates. As shown in Figure 4, neonatal colonic

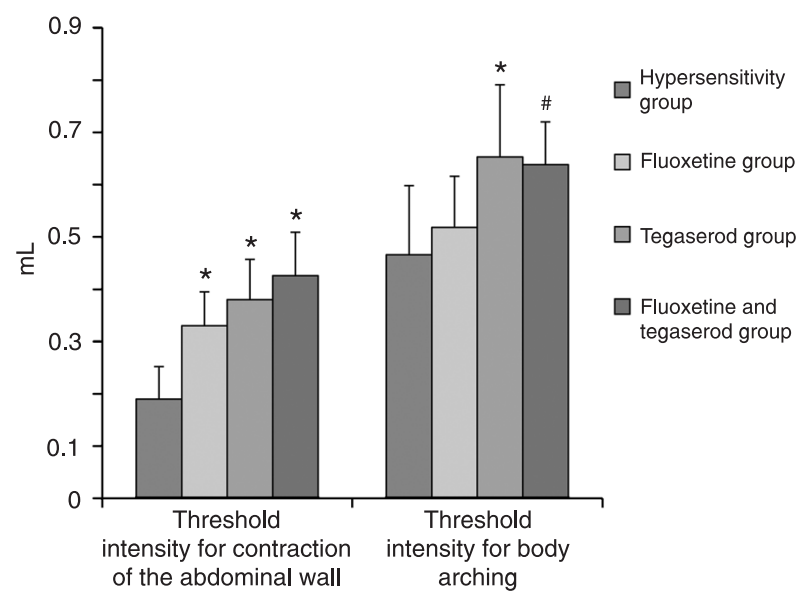

Figure 1. Effects of fluoxetine and tegaserod on visceral sensitivity ( $N=8$ per group). ${ }^{*} \mathrm{P}<0.01$ compared to the hypersensitivity group; \#P $<0.05$ compared to the hypersensitivity group (ANOVA).

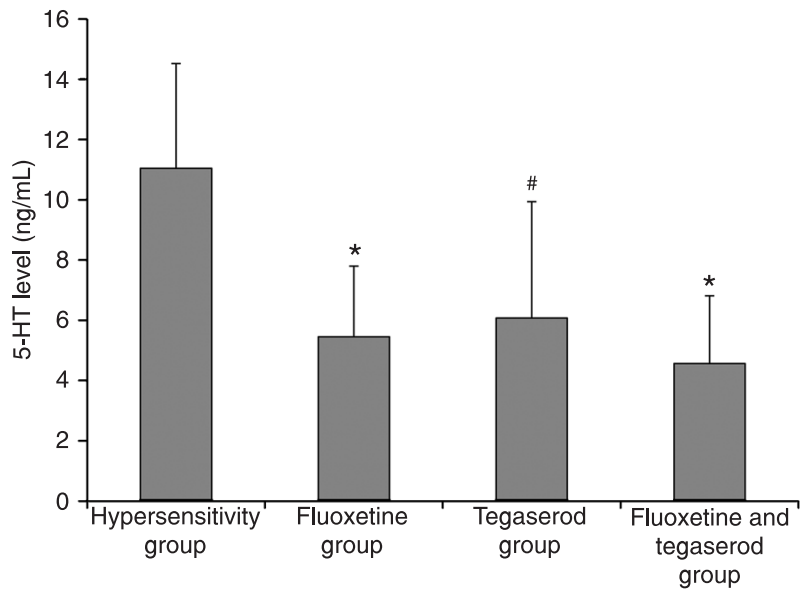

Figure 2. Plasma 5-HT content of different experimental groups ( $\mathrm{N}=8$ per group). ${ }^{*} \mathrm{P}<0.01$ compared to the hypersensitivity group; \#P $<0.05$ compared to the hypersensitivity group (ANOVA).

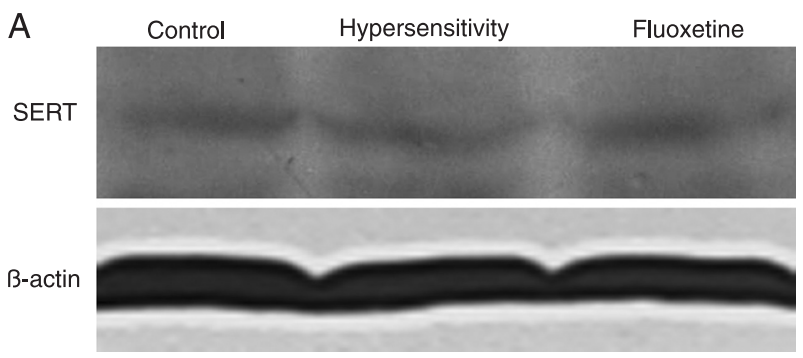

B

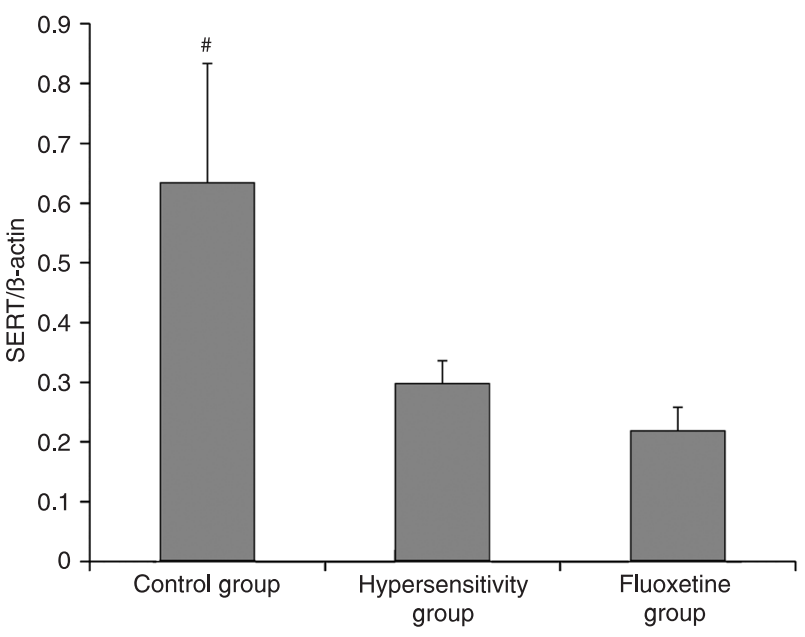

Figure 3. $A$, Western blotting of the serotonin transporter (SERT) in the proximal colon tissues. $B$, Quantitation of the human SERT protein in different groups compared to actin ( $N=3$ per group). ${ }^{\#} \mathrm{P}<0.05$ compared to the hypersensitivity group. There was no significant difference in SERT expression between the hypersensitivity group and the fluoxetine group (ANOVA). 
irritation increased the expression of the 5- $\mathrm{HT}_{4}$ receptor. We also found that fluoxetine treatment further increased its expression.

\section{Discussion}

Repeated stimulation of peripheral visceral sensitivity during early postnatal development can induce chronic visceral hyperalgesia, which is a well-defined model of visceral hypersensitivity resembling IBS (10). In the present study, we have validated a rat model of chronic visceral hypersensitivity with transient colonic irritation by $0.5 \%$ acetic acid during the neonatal period, in which no remarkable histopathological changes were observed. Using this model, we found increased expression of $5-\mathrm{HT}_{4}$ receptor and reduced SERT expression in colon tissues compared to control. Also, we found that a partial $5-\mathrm{HT}_{4}$ receptor agonist and selective serotonin reuptake inhibitor could improve visceral hypersensitivity, presumably through 5-HT signaling.

Compared to control, the animals in the visceral hypersensitivity group had higher levels of $5-\mathrm{HT}_{4}$ receptor in colon tissues. A recent study has suggested that $5-\mathrm{HT}_{4}$ receptors are involved in neurogenesis in the enteric nervous system (23). Local neurogenesis is responsible for the visceral hypersensitivity observed here. The $5-\mathrm{HT}_{4}$ receptor is a G-protein-coupled receptor and increases intracellular cyclic adenosine monophosphate (24). As a $5-\mathrm{HT}_{4}$ receptor partial agonist, tegaserod has been suggested to reduce colonic sensitivity both in animals (16) and humans (25), but the related mechanisms have not been clearly established. In addition to competing with endogenous 5-HT to functionally antagonize peripheral $5-\mathrm{HT}_{4}$ receptors in order to reduce afferent transmission (26), tegaserod can influence the local 5-HT concentration through its negative feedback regulation of 5 -HT release from EC cells $(27,28)$ or by inhibiting SERT (29). As an enteric neurotransmitter and a paracrine messenger from EC cells, 5-HT plays an important role in bowel physiology (30). In addition to increasing peristalsis and secretion, 5-HT has been thought to participate in mucosal sensory transduction (31). Our finding that tegaserod significantly reduces plasma $5-\mathrm{HT}$ levels suggests that tegaserod acts more like an autoreceptor agonist of EC cells than an inhibitor of SERT.

SERT is essential for serotonin clearance and is critical for serotonin homeostasis both at central 5-HT synapses and in the gut (32). In the gut, SERT is present both in the mucosa and in nerves of the enteric nervous system (33).
Abnormalities in serotonin reuptake can alter enteric serotonergic signaling, leading to sensory, motor, and secretory gut dysfunctions, which contribute to the pathophysiology of IBS (34). The functions of SERT depend on its membrane expression (35). Although different results have been reported $(9,36)$, most studies support the view that the SERT expression is reduced in IBS patients compared to healthy subjects $(6,37)$. The next question, however, is how does this reduction of SERT change visceral sensation. SSRIs can rapidly inhibit 5-HT uptake, but studies have shown that, in healthy subjects, acute SERT inhibition by administration of the selective 5-HT reuptake inhibitor citalopram does not induce changes in colonic sensitivity (38). It seems that therapeutic effects are obtained only after prolonged treatment. These results suggest that, in addition to the inhibition of 5-HT reuptake, other long-term adaptive changes occur and may contribute to the improvement of visceral sensitivity (39). In the present study, the administration of fluoxetine for 7 days to rats with chronic visceral hypersensitivity diminished visceral hypersensitivity. At the same time, we 
found increased $5-\mathrm{HT}_{4}$ receptor expression in the SSRI group. In view of the reduced plasma $5-\mathrm{HT}$ levels in this group, in addition to the inhibition of the 5-HT reuptake during the fluoxetine treatment, the adaptive compensation of the $5-\mathrm{HT}_{4}$ receptor may be one of the reasons for the diminished visceral hypersensitivity. We also found that SSRIs did not influence SERT expression, in agreement with previous reports (40). A recent in vitro study has shown that long-term fluoxetine treatment can reduce the availability of the transporter in the membrane without altering either the level of human SERT mRNA or the total amount of human SERT protein (39), suggesting that SSRIs mainly play a role in the gut at the postsynaptic level and induce postsynaptic 5-HT receptor activation (24).

We observed changes in $5-\mathrm{HT}_{4}$ receptors and SERT in a rat model of chronic visceral hypersensitivity and found that modulators of $5-\mathrm{HT}_{4}$ receptors and SERT could influence visceral sensitivity partly through their impact on 5-HT

\section{References}

1. Mawe GM, Coates MD, Moses PL. Review article: intestinal serotonin signalling in irritable bowel syndrome. Aliment Pharmacol Ther 2006; 23: 1067-1076.

2. Talley NJ, Spiller R. Irritable bowel syndrome: a little understood organic bowel disease? Lancet 2002; 360: 555-564.

3. Crowell MD. Role of serotonin in the pathophysiology of the irritable bowel syndrome. Br J Pharmacol 2004; 141: 12851293.

4. Gershon MD. Review article: serotonin receptors and transporters - roles in normal and abnormal gastrointestinal motility. Aliment Pharmacol Ther 2004; 20 (Suppl 7): 3-14.

5. Camilleri M. Serotonergic modulation of visceral sensation: lower gut. Gut 2002; 51 (Suppl 1): i81-i86.

6. Coates MD, Mahoney CR, Linden DR, Sampson JE, Chen $\mathrm{J}$, Blaszyk $\mathrm{H}$, et al. Molecular defects in mucosal serotonin content and decreased serotonin reuptake transporter in ulcerative colitis and irritable bowel syndrome. Gastroenterology 2004; 126: 1657-1664.

7. Dunlop SP, Coleman NS, Blackshaw E, Perkins AC, Singh G, Marsden CA, et al. Abnormalities of 5-hydroxytryptamine metabolism in irritable bowel syndrome. Clin Gastroenterol Hepatol 2005; 3: 349-357.

8. Sikander A, Rana SV, Prasad KK. Role of serotonin in gastrointestinal motility and irritable bowel syndrome. Clin Chim Acta 2009; 403: 47-55.

9. Kerckhoffs AP, Ter Linde JJ, Akkermans LM, Samsom M. Trypsinogen IV, serotonin transporter transcript levels and serotonin content are increased in small intestine of irritable bowel syndrome patients. Neurogastroenterol Motil 2008; 20: 900-907.

10. Al-Chaer ED, Kawasaki M, Pasricha PJ. A new model of chronic visceral hypersensitivity in adult rats induced by colon irritation during postnatal development. Gastroenterology 2000; 119: 1276-1285.

11. Liu YB, Yuan YZ, Tao RJ, Zhai ZK, Chen HZ. Establishment of a rat model of gut hypersensitivity and for evaluation of visceral sensitivity. Chin J Dig 2003; 23: 34-37. signaling. The influence of SSRIs on $5-\mathrm{HT}_{4}$ receptors may explain the relationship between different factors in the pathogenesis of visceral hypersensitivity in IBS.

Some limitations of our study should be noted. Serotonin release in the GI tract and its plasma levels can be affected by a number of variables, and the possibility that SSRIs induce analgesia through central actions could not be ruled out in our study. Although it is becoming increasingly clear that changes in 5-HT signaling occur in IBS, the related mechanism is far from thoroughly understood. Further studies are needed to better understand the pathogenesis of visceral hypersensitivity in order to improve the treatment of IBS.

\section{Acknowledgments}

Research supported by the National Natural Science Foundation of China (Grant \#30600275, 2007)
12. Winston J, Shenoy M, Medley D, Naniwadekar A, Pasricha PJ. The vanilloid receptor initiates and maintains colonic hypersensitivity induced by neonatal colon irritation in rats. Gastroenterology 2007; 132: 615-627.

13. Chen JX, Pan H, Rothman TP, Wade PR, Gershon MD. Guinea pig 5-HT transporter: cloning, expression, distribution, and function in intestinal sensory reception. $A m \mathrm{~J}$ Physiol 1998; 275: G433-G448.

14. Appel S, Kumle A, Hubert M, Duvauchelle T. First pharmacokinetic-pharmacodynamic study in humans with a selective 5-hydroxytryptamine4 receptor agonist. J Clin Pharmacol 1997; 37: 229-237.

15. Zink M, Rapp S, Gebicke-Haerter PJ, Henn FA, Thome J. Antidepressants differentially affect expression of complexin I and II RNA in rat hippocampus. Psychopharmacology 2005; 181: 560-565.

16. Schikowski A, Thewissen M, Mathis C, Ross HG, Enck P. Serotonin type-4 receptors modulate the sensitivity of intramural mechanoreceptive afferents of the cat rectum. Neurogastroenterol Motil 2002; 14: 221-227.

17. Krawisz JE, Sharon P, Stenson WF. Quantitative assay for acute intestinal inflammation based on myeloperoxidase activity. Assessment of inflammation in rat and hamster models. Gastroenterology 1984; 87: 1344-1350.

18. Linden DR, Chen JX, Gershon MD, Sharkey KA, Mawe GM. Serotonin availability is increased in mucosa of guinea pigs with TNBS-induced colitis. Am J Physiol Gastrointest Liver Physiol 2003; 285: G207-G216.

19. Dizeyi N, Bjartell A, Hedlund P, Taskén KA, Gadaleanu V, Abrahamsson PA. Expression of serotonin receptors 2B and 4 in human prostate cancer tissue and effects of their antagonists on prostate cancer cell lines. Eur Urol 2005; 47: 895-900.

20. Bian X, Patel B, Dai X, Galligan JJ, Swain G. High mucosal serotonin availability in neonatal guinea pig ileum is associated with low serotonin transporter expression. Gastroenterology 2007; 132: 2438-2447. 
21. Rachmilewitz D, Simon PL, Schwartz LW, Griswold DE, Fondacaro JD, Wasserman MA. Inflammatory mediators of experimental colitis in rats. Gastroenterology 1989; 97: 326-337.

22. Bearcroft CP, Perrett D, Farthing MJ. Postprandial plasma 5-hydroxytryptamine in diarrhoea predominant irritable bowel syndrome: a pilot study. Gut 1998; 42: 42-46.

23. Liu MT, Kuan YH, Wang J, Hen R, Gershon MD. 5-HT receptor-mediated neuroprotection and neurogenesis in the enteric nervous system of adult mice. J Neurosci 2009; 29: 9683-9699.

24. Bockaert J, Claeysen S, Compan V, Dumuis A. 5-HT4 receptors: history, molecular pharmacology and brain functions. Neuropharmacology 2008; 55: 922-931.

25. Sabate JM, Bouhassira D, Poupardin C, Wagner A, Loria Y, Coffin B. Sensory signalling effects of tegaserod in patients with irritable bowel syndrome with constipation. Neurogastroenterol Motil 2008; 20: 134-141.

26. Grundy D. Towards a reduction of rectal pain? Neurogastroenterol Motil 2002; 14: 217-219.

27. Schworer H, Ramadori G. Autoreceptors can modulate 5-hydroxytryptamine release from porcine and human small intestine in vitro. Naunyn Schmiedebergs Arch Pharmacol 1998; 357: 548-552.

28. Gebauer A, Merger M, Kilbinger $\mathrm{H}$. Modulation by $5-\mathrm{HT}_{3}$ and $5-\mathrm{HT}_{4}$ receptors of the release of 5-hydroxytryptamine from the guinea-pig small intestine. Naunyn Schmiedebergs Arch Pharmacol 1993; 347: 137-140.

29. Ismair MG, Kullak-Ublick GA, Blakely RD, Fried M, Vavricka SR. Tegaserod inhibits the serotonin transporter SERT. Digestion 2007; 75: 90-95.

30. Liu MT, Rayport S, Jiang Y, Murphy DL, Gershon MD. Expression and function of $5-\mathrm{HT}_{3}$ receptors in the enteric neurons of mice lacking the serotonin transporter. Am J Physiol Gastrointest Liver Physiol 2002; 283: G1398-G1411.

31. Gershon MD. Review article: roles played by 5-hy- droxytryptamine in the physiology of the bowel. Aliment Pharmacol Ther 1999; 13 (Suppl 2): 15-30.

32. Narboux-Neme N, Pavone LM, Avallone L, Zhuang X, Gaspar P. Serotonin transporter transgenic (SERTcre) mouse line reveals developmental targets of serotonin specific reuptake inhibitors (SSRIs). Neuropharmacology 2008; 55: 994-1005.

33. Wade PR, Chen J, Jaffe B, Kassem IS, Blakely RD, Gershon MD. Localization and function of a 5-HT transporter in crypt epithelia of the gastrointestinal tract. $J$ Neurosci 1996; 16 : 2352-2364.

34. Colucci R, Blandizzi C, Bellini M, Ghisu N, Tonini M, Del Tacca M. The genetics of the serotonin transporter and irritable bowel syndrome. Trends Mol Med 2008; 14: 295304.

35. Spiller R. Serotonin and GI clinical disorders. Neuropharmacology 2008; 55: 1072-1080.

36. Camilleri M, Andrews CN, Bharucha AE, Carlson PJ, Ferber I, Stephens D, et al. Alterations in expression of $\mathrm{p} 11$ and SERT in mucosal biopsy specimens of patients with irritable bowel syndrome. Gastroenterology 2007; 132: 17-25.

37. Bellini M, Rappelli L, Blandizzi C, Costa F, Stasi C, Colucci $R$, et al. Platelet serotonin transporter in patients with diarrhea-predominant irritable bowel syndrome both before and after treatment with alosetron. Am J Gastroenterol 2003; 98: 2705-2711.

38. Tack J, Broekaert D, Corsetti M, Fischler B, Janssens J. Influence of acute serotonin reuptake inhibition on colonic sensorimotor function in man. Aliment Pharmacol Ther 2006; 23: 265-274.

39. Iceta R, Mesonero JE, Alcalde Al. Effect of long-term fluoxetine treatment on the human serotonin transporter in Caco-2 cells. Life Sci 2007; 80: 1517-1524.

40. Linnet K, Koed K, Wiborg O, Gregersen N. Serotonin depletion decreases serotonin transporter mRNA levels in rat brain. Brain Res 1995; 697: 251-253. 